\title{
Control of astigmatism after surgery and trauma
}

\author{
M. J. ROPER-HALL
}

From Birmingham

SUMMARY Since the introduction of microsurgical accuracy in the closure of corneal wounds, there have been fewer complications due to imperfect wound closure. As a result the eye is much safer after intraocular surgery or trauma. There may, however, be an undesirable and irregular refractive error. Much thought has been given to the prevention of this by attention to other details during closure of wounds. Interest has been revived in surgery for the correction of inherent refractive errors. The methods used for such conditions may also be applied to residual distortion after surgery or trauma. The possibility of adjustment during the early postoperative period has escaped detailed consideration. This neglected approach to the control of astigmatism is discussed in this paper.

Most postoperative astigmatism is due to inaccurate wound closure. Attempts have recently been made ${ }^{1-5}$ to prevent this by detailed attention to surgical technique assisted by operating keratometers. When this is unsuccessful, a secondary corrective procedure involving resection, grafting, or keratotomy can be applied. Despite these efforts some patients end up with a gross astigmatism in an otherwise good eye. It is sometimes suggested that such astigmatism can be reduced by suture removal, but this is not very predictable and sometimes it can be made worse.

Adjustment of a continuous suture or removal of one or more selected interrupted sutures during the early postoperative weeks can allow a refined control. This possibility has been given scant attention but has a number of advantages. It can be applied at the time of postoperative consultation and refraction assessment. The effect is often dramatic and immediate and is subject to less subsequent alteration than secondary operative procedures. It can be applied to corneal distortion following trauma as well as cataract extraction and keratoplasty. It sets aside some of the difficulties in predicting the final refractive error at the time of primary surgery.

\section{Surgically induced astigmatism}

The pattern of surgically induced astigmatism was well known at the end of the last century and several authors studied ways of controlling it. ${ }^{67}$

Wound slide in a classical cataract section usually

Correspondence to Mr M. J. Roper-Hall, 38 Harborne Road. Edgbaston. Birmingham B15 3HE. causes a fairly regular astigmatism 'against the rule.' The nearer the wound to the centre of the cornea, the greater the astigmatism. It follows that traumatic lacerations near the corneal periphery usually cause regular astigmatism, with flattening of the meridian at right angles to the scar. This is equivalent to a convex $(+)$ cylinder with its axis parallel to the wound. If the damage extends to involve the central cornea, there is irregular and often gross astigmatism.

Wound closure has become much more secure and accurate since the advent of microsurgery. This has greatly reduced the incidence of postoperative complications such as hyphaema, iris prolapse, wound leakage, and shallow anterior chamber, which are related to defective wound healing. However, firm wound closure can induce astigmatism, and in cataract surgery, contrary to previous experience, this is usually 'with the rule.'

Many papers have been published on this surgically induced astigmatism and how to control it. ${ }^{1-5}$ Most of them consider ways in which it can be prevented by surgical technique and by intraoperative keratometry.

Careful realignment and apposition of the wound while suturing can make it watertight without being overtightened. During closure judgment is assisted by the presence of an air bubble in the anterior chamber, which highlights stress lines in the cornea if the suture is too tight or the wound misaligned.

In recent years various forms of keratometer have been designed for use with the operating microscope in the hope of obtaining the desired firmness and regularity of wound closure so that an ideal postoperative refraction results. There are difficulties in achieving this. Accuracy is limited with simple 
keratometers, which utilise an illuminated ring reflecting a circle of light from the corneal surface, and up to 3 dioptres of astigmatism may be present even when the reflection appears to indicate a spherical form. This is little or no better than surgical control under the microscope alone.

More accurate keratometers can be used during planned surgery, ${ }^{8}$ but even if the desired corneal curvature is obtained at the end of operation the final postoperative refraction is still not fully predictable. Conditions at the end of surgery are abnormal, healing processes are subject to many variables, and these often lead to changing refraction.

At the end of operation the eye will usually be hypotensive, and this could affect the measurements. The ultimate refraction will depend upon the healing process in the tissues and may not be equally rapid in all parts. This will be affected by factors individual to the patient. The way in which the tissues react to the suture material is also variable, and some sutures may cut tissue by a necrotic process due to overtightness. The final astigmatism will be influenced too by the extent of the incision; even a small wound may have much astigmatism, and some extensive wounds can show little cylinder due to neutralisation of astigmatic forces.

Since the final refractive error after full-thickness corneal incision is subject to so many variables, a keratometer may not prove to be so practical a clinical tool as it may seem.

\section{Refractive surgery}

Attempts have been made in the past to control refractive errors by corneal sculpturing (keratomileusis) or relaxing incision (keratotomy), ${ }^{69-11}$ and the latter has been given renewed attention more recently. ${ }^{12}{ }^{13}$ Public interest has been aroused by the suggestion that radial keratotomy can correct errors which would otherwise require the lifetime wearing of spectacles. It has attracted patients with relatively low myopia, and many have submitted themselves to surgery, with as yet uncertain end results.

Although the effect of nonperforating wounds on astigmatism was studied by Lans in $1898{ }^{6}$ it was Sato whose name is most usually associated with early attempts at refractive surgery. ${ }^{1011} \mathrm{He}$ wrote with great enthusiasm of his methods and their results, claiming that the operation was indicated for all cases of astigmatism over 2 dioptres. Serious complications were encountered, and after a few years the procedure was generally condemned.

After his experience of using radial keratotomy, with which he claims to have had no complications over a period of 5 years, Fyodorov ${ }^{12}$ has during the past 4 years studied the effect of applying anterior keratotomy incisions to the correction of astigmatism. He reports excellent results in 126 eyes of 76 patients and describes different patterns of incision for different degrees of astigmatism. Most of these are related to errors up to 4 dioptres. In the experience of other surgeons the method does not seem to be free of complication, and some reports of adverse effects of the more recent operations are now being made. ${ }^{13}$

It may be more difficult, as Fyodorov states, to treat high refractive errors, but there is a greater need to apply our efforts to the control of irregular astigmatism which cannot be corrected by spectacles or contact lenses than the refractive errors for which these optical appliances can so easily be used.

The methods introduced for the surgical reduction of refractive errors can also be applied to the correction of surgically or traumatically induced errors, but it is undesirable that a second operative procedure should be required for correction of such errors after planned surgery.

\section{Adjustment of astigmatism in the postoperative phase}

A cornea with a large incision can show quite substantial alterations of refraction during the first 8 postoperative weeks. Thereafter it becomes more stable, and after a year little alteration is seen.

It is unsafe to remove all corneal sutures at an early stage, and, although it has been stated that their removal will reduce astigmatism, this is by no means consistent (Table 1). However, since the cornea is subject to variation during the early weeks of healing, there is an opportunity of adjusting an astigmatic refraction. This possibility has escaped detailed consideration, but very effective adjustments can be made, and these may control larger errors than are amenable to refractive surgery.

\section{Method}

Selected suture removal is applied to wounds closed by interrupted sutures. Continuous sutures can be adjusted without removal. Both these actions can be undertaken at the slit-lamp with topical anaesthesia.

INTERRUPTED SUTURES

Provided sutures have been placed at intervals no greater than $1.5 \mathrm{~mm}$ apart it is possible to remove

Table 1 Comparison of astigmatism at 6 months with that after 2 years: 283 corneal wounds

$\begin{array}{lr}\text { Power unchanged } & 109 \\ \text { Less astigmatism } & 120 \\ \text { More astigmatism } & 54\end{array}$


Fig. 1 Selected suture removal.

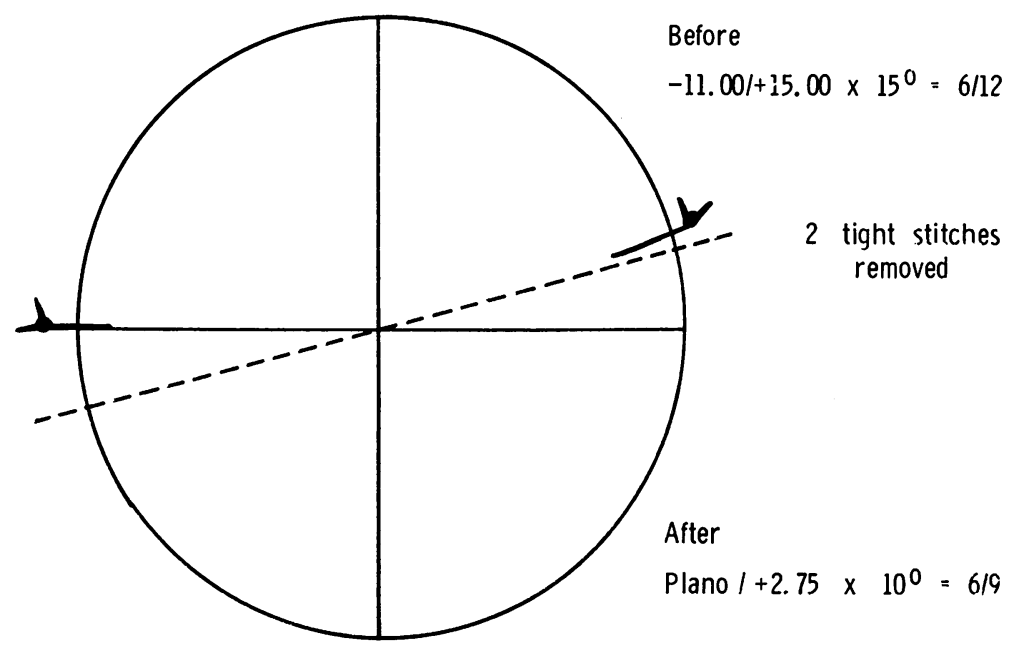

individual sutures without threatening wound security.

Usually a tight suture will be found on the axis of the + cylinder, and, if this is removed, there is an immediate reduction of astigmatism. The refraction can then be reassessed and the process repeated until the optimal correction is obtained.
CONTINUOUS SUTURES

It is possible to adjust the tension of a continuous suture by sliding it along the wound.

The power and axis of astigmatism is established. Microsurgical suture forceps can then be used to grip the continuous polyester suture through the corneal epithelium and ease it towards the tight meridian (the

\section{SUTURE ADJUSTMENT}

SIX WEEKS POST-OP

Before

$+6.00 \times 130^{\circ}$

After

$+3.50 \times 120^{\circ}$

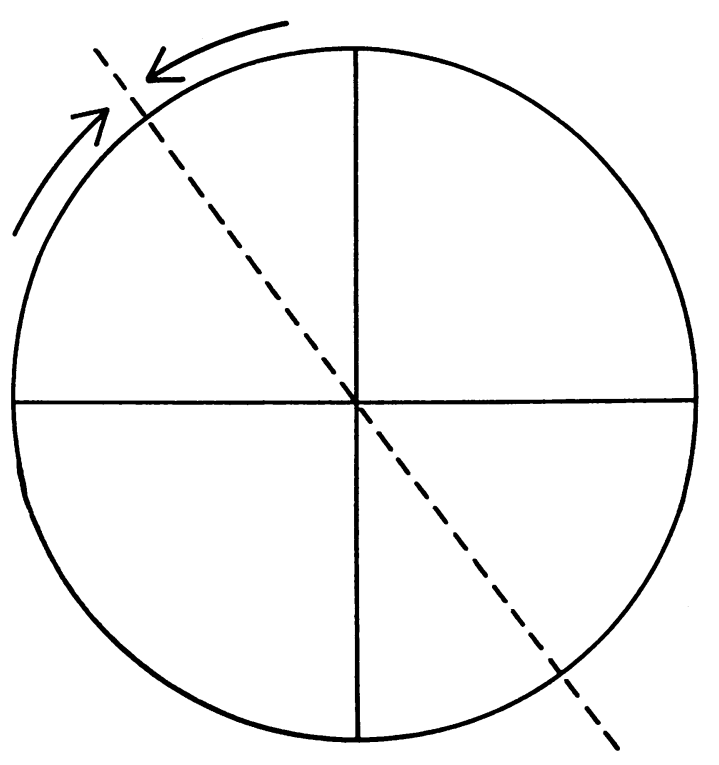

EIGHT WEEKS POST-OP

Before

$+4.50 \times 135^{\circ}$

After

$+1.00 \times 160^{\circ}$

Fig. 2 Suture adjustment. 
+ axis). The change of refraction is usually immediate, and after reassessment the adjustment can be repeated if necessary.

\section{Case reports}

A large series of cases is being analysed to quantify the method, but 2 examples will illustrate the potential of the 2 methods.

SELECTED SUTURE REMOVAL (Fig. 1)

Case 1. Manager aged 52 years. Old herpes simplex.

11 Jan 1981. Right penetrating keratoplasty $7.5 \mathrm{~mm}$ into $7 \mathrm{~mm} ; 8$ interrupted and 1 continuous $10 / 0$ nylon suture.

12 Mar 1981. $-11 \cdot 00 /+15 \cdot 00$ axis $15^{\circ}=6 / 12+$.

18 Jun 1981. No change in refraction. Tight $10 / 0$ sutures removed at 2.30 and 9 o'clock. Immediate change of refraction to $+2 \cdot 75$ axis $10^{\circ}=6 / 9$.

Comment. Immediate reduction of 12 dioptres of astigmatism when selected sutures removed 5 months after operation.

In keratoplasty, owing to the more central incision and slower healing, the adjustment can be made later in the postoperative period than is the case with incisions near the corneal periphery.

SUTURE ADJUSTMENT (Fig. 2)

Case 2. Retired administrator aged 60 years. Cataract.

26 Sep 1980. Right cataract extraction. Interrupted $8 / 0$ silk suture at 12 o'clock and continuous $10 / 0$ nylon from 9 to 3 o'clock with anchoring loops at each end.

6 Nov $1980 .+6 \cdot 00$ axis $130^{\circ} .10 / 0$ suture eased to 10 o'clock. Immediate change of refraction to $+3 \cdot 50$ axis $120^{\circ}$.

20 Nov 1980 . $+4 \cdot 50$ axis $135^{\circ}$. Suture eased to 10.30 o'clock. Immediate change of refraction to $+1 \cdot 00$ axis $160^{\circ}$.

29 Oct $1981.6 / 5$ unaided. $10 / 0$ suture intact.

Comment. Immediate reduction of astigmatism when suture eased towards the tight meridian 6 and 8 weeks after surgery. This reduction of 5 dioptres has been maintained.

\section{Conclusion}

There are a number of ways in which corneal astigmatism can be prevented or treated. As soon as accurate refraction is possible, the early postoperative period of wound healing allows accurate adjustment with the convenience of simplicity.

\section{References}

1 Bedrossian PB, Sabater G. Troutman RC. Induced astigmatism as a result of surgery. Proc 1st S African Intern Ophthalmol Symp 1969; 219-25.

2 Jaffe $\mathrm{N}$. Corneal astigmatism change related to cataract incision location. Proc 2nd Biennial Cataract Surg Congr. Miami: Educational Press 1971: 366-9.

3 Troutman RC. Corneal astigmatism change related to cataract incision location. Proc 2nd Biennial Cataract Surg Congr. Miami: Educational Press, 1971: 370.

4 Troutman RC. Microsurgical control of corneal astigmatism in cataract and keratoplasty. Trans Am Acad Ophthalmol Otolaryngol 1973; 77: 563-72.

5 Troutman RC. Repair of corneal wounds and the elimination of astigmatism. Trans Ophthalmol Soc UK 1978; 98: 49-50.

6 Lans LJ. Experimentelle Untersuchungen über Entstehung von Astigmatismus durch nicht-perforirende Corneawunden. Albrecht von Graefes Arch Klin Ophthalmol 1898; 45: 117-52.

7 Weber A. Operative Beseitigung des Astigmatismus. Congr Ophthalmol 1900; 612-5.

8 Colvard DM, Kratz RP, Mazzocco TR, Davidson B. Clinical evaluation of the Terry surgical keratometer. Am Intraocular Implant Soc J 1980; 6: 249-51.

9 Barraquer JI. 'Queratomileusis' para la correccion de la myopia. An Inst Barraquer 1964; 5: 206-29.

10 Sato T. Posterior incision of cornea. Am J Ophthalmol 1950; 33: 943-8.

11 Sato T. Posterior half incision of cornea for astigmatism. Am J Ophthalmol 1953; 36: 462-6.

12 Fyodorov S. Surgical correction of myopia and astigmatism. In: Schachar RA, Levy NS, Schachar L, eds. Keratorefraction. Proc Keratorefractive Soc, PO 145, Denison, Texas, 1980: 141-72.

13 Yamaguchi T, Kaufman HE, Sukushima A, Sasira A, Asbell PA. Anterior radial keratotomy. AmerJOphthalmol 1981:92: 313-27. 